
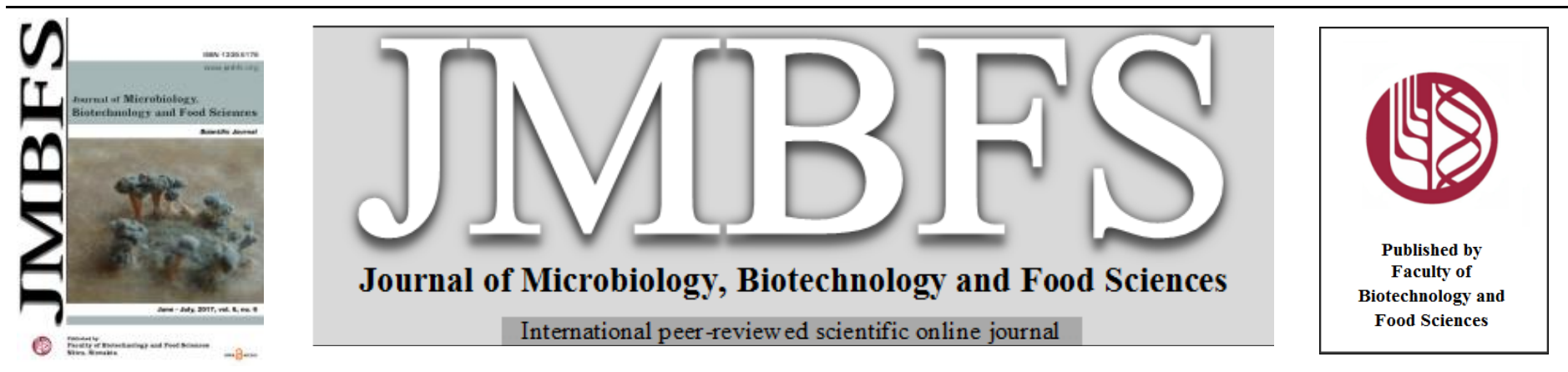

\title{
PREPARATION OF PLANT VECTOR CONSTRUCT CONTAINING DEHYDRIN GENE At2g21490
}

\author{
Mária Zimová ${ }^{1,2}$, Eva Boszorádovál, Zuzana Gregorová ${ }^{1}$, Ildikó Matušíkováa ${ }^{3}$ Jana Moravčíková ${ }^{*}$ \\ Address(es): Ing. Jana Moravčíková, PhD., \\ ${ }^{1}$ Institute of Plant Genetics and Biotechnology Slovak Academy of Sciences, Akademická 2, P.O. Box 39A, SK-950 07 Nitra, Slovak Republic. \\ ${ }^{2}$ Department of Botany and Genetics, Faculty of Natural Sciences, The Constantine Philosopher University, Nábrežie mládeže 91 , SK-94974 Nitra, Slovak Republic. \\ ${ }^{3}$ Department of Ecochemistry and Radioecology, University of Cyril and Methodius, J. Herdu 2, Trnava, SK-917 01, Slovak Republic.
}

*Corresponding author: jana.moravcikova@savba.sk

doi: $10.15414 /$ jmbfs.2017.6.6.1261-1263

\section{ARTICLE INFO}

Received 8. 2. 2017

Revised 8. 3. 2017

Accepted 10. 5. 2017

Published 1. 6. 2017

Regular article

open $\odot$ access

\section{ABSTRACT}

This work is focused on preparation of a plant transformation vector pDH2 containing the expression unit of the dehydrin gene At2g21490 under a control of the constitutive $d C a M V 35 S$ promoter and the selectable marker neomycin phosphotransferase gene controlled by the nos promoter. The gene At2g21490 is classified as a dehydrin of the type $\mathrm{K}_{2} \mathrm{SY}_{2}$. The gene was isolated from Arabidopsis thaliana by PCR approach. The plasmid pDH2 was transformed into the strain Agrobacterium tumefaciens LBA 4404. The stability of the plasmid $\mathrm{pDH} 2$ in Agrobacterium has been verified by restriction analysis after re-transformation of the pDH2 into Escherichia coli.

Keywords: Agrobacterium tumefaciens, Arabidopsis thaliana, At2g21490, binary vector, dehydrins

\section{INTRODUCTION}

Due to the changes in the environment, plants are increasingly exposed to different types of abiotic stresses such as drought, salinity, low temperature or the presence of heavy metals. Among the proteins that are significantly accumulated during the stress caused by dehydration, osmoticum and/or a low temperature are LEA proteins ("Late embryogenesis abudant proteins") (Amara et al., 2014) They are hydrophilic molecules whose role probably is to protect biomolecules and cell membranes (Candat et al., 2014). Dehydrins (Pfam PF00257) are one of the most characterized group of LEA proteins. The LEPdb database currently contains over 380 records on dehydrins from various plant species and their physicochemical properties. Most of dehydrins are associated mainly with the process of embryogenesis, but they can also be accumulated in vegetative parts during the plant lifecycle. Generally, dehydrins are enriched with glycine and lysine residues, but they lack cysteine and tryptophan (Allagulova et al., 2003). The characteristic feature of all dehydrins is conservative sequences denominated as $\mathrm{K}$-, S- and Y-segmets which are their structural attribute. Five different subclasses of dehydrins are defined on the basis of the conserved segments: $\mathrm{Y}_{\mathrm{n}} \mathrm{SK}_{\mathrm{n}}, \mathrm{SK}_{\mathrm{n}}, \mathrm{K}_{\mathrm{n}}, \mathrm{Y}_{\mathrm{n}} \mathrm{K}_{\mathrm{n}}$, and $\mathrm{K}_{\mathrm{n}}$ (Close, 1997). The presence of K-segment is obligate for all groups of dehydrins.

Dehydrins are considered as multifunctional proteins that can bind to macromolecules such as nucleic acid, have a protective role, can bind free metals, and can act as chaperones or antioxidants (Rorat et al. 2004; Hara, 2010). In term of the structure and the presence of characteristic protein domains, they are divided into several groups. So far, 10 dehydrin genes were identified in Arabidopsis (Hundertmark and Hincha, 2008). All of these genes contain histidine rich regions (His). Since the structures His-X3-His and His-His show strong affinity to metals (Hara et al., 2005), it was supposed they can reduce various types of cellular damage during metal stress. The regions rich in His may play a role in buffering and/or may serve as sensors of the levels of metals (Hara, 2010) or could be involved in the reduction of "reactive oxygen species" (ROS) (Hara et al., 2013).

The Arabidopis gene At $2 \mathrm{~g} 21490$ is classified as a dehydrin of the type $\mathrm{K}_{2} \mathrm{SY}_{2}$. It is expressed in late stages of seed formation and completely absent in vegetative tissues. The gene possesses 14 His residues, two His-X3-His and one His-His sequences (Hara, 2010).

In this work we prepared a plant transformation vector $\mathrm{pDH} 2$ containing the gene At $2 \mathrm{~g} 21490$ under control of the constitutive double $d C a M V 35 S$ promoter. The gene At2g21490 was isolated from Arabidopsis thaliana by PCR approach. The binary vector $\mathrm{pDH} 2$ was transformed into the strain Agrobacterium tumefaciens LBA 4404. The stability of the plasmid $\mathrm{pDH} 2$ in Agrobacterium has been verified by restriction analysis after re-transformation of the $\mathrm{pDH} 2$ into Escherichia coli.

\section{MATERIAL AND METHODS}

\section{Izolation of the gene At $2 \mathrm{~g} 21490$}

The genomic DNA from Arabidpopsis thaliana was isolated according to the Chen et al. (1992). The sequence of the gene At $2 \mathrm{~g} 21490$ was amplified using the combination of the primers P1 (5'-GGTAATAATACCATGGGGGATTTGAG$\left.3^{\prime}\right)$ and P2 (5'-GCTAGCAAAATACAGTTCCTTC-3'). The PCR reaction was carried out in $25 \mu 1$ mixture containing $100-200 \mathrm{ng}$ of DNA template, $20 \mathrm{pmol}$ of each primer (forward, reverse), $200 \mu \mathrm{M}$ dNTPs, 1x PCR buffer and 1 unit of Taq DNA polymerase. The first PCR step of $95^{\circ} \mathrm{C}$ for 4 minutes was followed by 35 cycles: $95^{\circ} \mathrm{C}-45 \mathrm{~s} ; 63^{\circ} \mathrm{C}-45 \mathrm{~s}$ and $72^{\circ} \mathrm{C}$ for 2 minutes. The last step was performed at $72^{\circ} \mathrm{C}$ for 10 minutes. The PCR product was isolated from the gel using QIAquick Gel Extraction Kit (Qiagen). The identity of the PCR product was confirmed by sequencing.

\section{Plant vector construct}

The PCR product was ligated into the plasmid pGEm-T® Easy (Promega) to yield pZM1. Subsequently, a 1037 bp EcoRI-EcoRI fragment from pZM1 was ligated into EcoRI-EcoRI-digested plasmid pBSK+ to create pZM2. The plasmid pZM3 was created by cloning of $d C a M V 35 S$ as HindIII-NcoI fragment from plasmid pBS4 and 762 bp NcoI-ClaI fragment from pZM9 into the vector pUN (Vaculkova et al., 2007). The plant transformation vector $\mathrm{pDH} 2$ was obtained by ligation of $d C a M V 35 S / D H 2 / p o l y A$ as EcoRI-XbaI fragment into EcoRI-XbaIdigested binary vector pBINPlus (Van Engelen, 1995). The binary vector pDH2 was introduced into Agrobacterium tumefaciens strain LBA 4404 using method „triparental matting“ (Matzke and Matzke, 1986).

\section{Stability of the plasmid pDH2 in A. tumefaciens}

The stability was verified using restriction analysis after isolation of the plasmid $\mathrm{pDH} 2$ from A. tumefaciens and re-transformation into $E$. coli. 


\section{RESULTS AND DISCUSSION}

To study the function of the dehydrin gene At2g21490 in tolerance to selected abiotic stresses using transgenosis, the plant transformation vector $\mathrm{pDH} 2$ was prepared. The T-DNA of the $\mathrm{pDH} 2$ contained the gene At2g21490 under control of constitutive $d C a M V 35 S$ promoter and the selectable neomycin phosphotransferase gene (nptII) under control of the nos promoter. The cloning strategy is given in Figure 1.

The specific primers $\mathrm{P} 1 / \mathrm{P} 2$ were designed to amplify a PCR product $\mathrm{P} 1-\mathrm{P} 2$ of a size $1,037 \mathrm{~kb}$ that contained the sequence $\mathrm{DH} 2 /$ polyA. The plasmid pZM1 was created by ligation of the PCR product into the cloning vector pGEm-T® Easy. The identity of the amplified sequence was confirmed by sequencing. The sequence was compared with the sequence of the gene At2g21490 using the programe Clustal Omega (Figure 2).

The PCR product was ligated as EcoRI-EcoRI fragment of the plasmid pZM1 into the vector pBSK+ to yield plasmid pZM2. The identity of the inserted fragment was verified by restriction analysis (data not shown).

The next step of the cloning strategy was ligation of the sequence $\mathrm{DH} 2 /$ polyA from the pZM2 and the sequence of the $d C a M V 35 S$ promoter into the cloning vector pUN. Subsequently, the sequence of the expression unit $d C a M V$ $35 \mathrm{~S} / \mathrm{DH} 2 /$ polyA was ligated into the binary vector $\mathrm{pBinPlus.} \mathrm{This} \mathrm{vector} \mathrm{contains}$ the selectable nptII gene encoding resistance to antibiotic kanamycin. The identity of the plasmid pDH2 was confirmed by restriction analyses. In Figure 3 the position of restriction enzymes used in the analyses is given. The results of restriction analyses are in Figure $3 b$.

Based on our previous experiences with instability of some sequences in bacteria (Vaculkova $\boldsymbol{e t}$ al., 2007), the stability of the sequence of the T-DNA region was analysed using restriction analyses after re-transformation of the plasmid $\mathrm{pDH} 2$ from A. tumefaciens into E.coli. After retransformation, totally, 30 clones were isolated and subjected to restriction analyses. Restriction profiles of all analysed clones corresponded with expected (Figure 4).

p $\mathbf{Z M 1}$

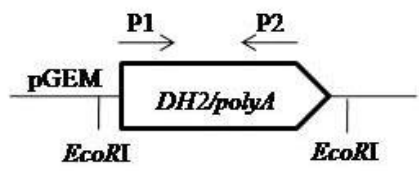

PZM2

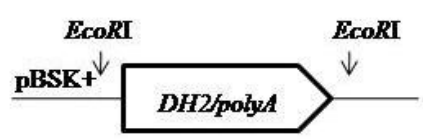

DZMB

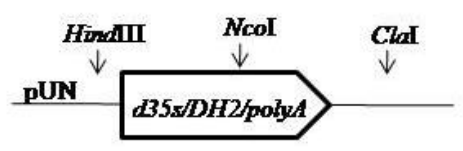

pDH2

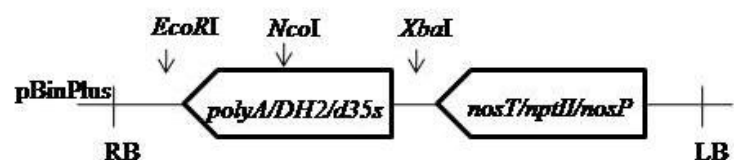

Figure 1 Cloning strategy. The arrows indicate restriction enzymes used in individual cloning steps. $d 35 s$ - double $C a M V 35 S$ promoter, $d h 2$ - dehydrin gene, poly $A$ - poly sequence of gene $\mathrm{DH} 2$, nos $T$ - nos terminator, npt II - neomycin phosphotransferase gene, nos $P$ - nos promoter
pZM1

At2g21490

GGTAATAATACCATGGGGATTTGA GGGACGAAAAAGGTAATCCGATCCATCTAAC GGTAATAATATAATGGGGGATTTGAEGGACGAAAAAGGTAATCCGATCCATCTAAC

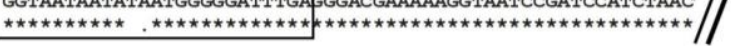

pZM1 ACACAGGGAAACCCAATTGTCGACCTGACTGATGAGCACGGTAACCCCATGTACCTAACC ACACAGGGAAACCCAATTGTCGACCTGACTGATGAGCACGGTAACCCATGTACCTAACC

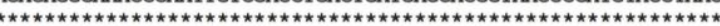

At2g21490

AgAAGGGCATTCTCGAGAAGATCAAGGACAAGCTTCCAGGCCACCATAACCACAACC /

pZM1 AGAAGGGCATTCTCGAGAAGATCAAGGACAAGCTTCCAGGCACCATACCACACAAC

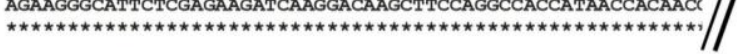

pzM1

At2g21490

CATGAACACCAATCATATGACGTCTTTGTTACATGAATAAATCGTTTGCACGAATTTCAT CATGAACACCAATCATATGACGTCTTTGTTACATGAATAAATCGTTTGCACGAATTTCAT

pZM1

At2g21490

TAGGGCTTATGAAGAATCAATATATATGTCTAGTGAAGTTTACTAAATTTTAGTTGTGTT TAGGGCTTATGAAGAATCAATATATATGTCTAGTGAAGTTTACTAAATTTTTAGTTGTGTT TAGGGCTTATGAAGAATCAATATATATGTCTAGTGAAGTTTACTAAATTTTAGTTGTGT

TGCTTGCAGTTTGTGAATGTGACCATCGTGTTATCATGTTCTTGTTPATTTATAA GAAC

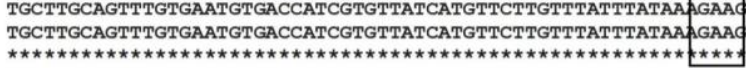

pZM1 21490

pZM1

At2g21490

\section{GAACTGTATTTTGCTAGC}

GAACTGTATTTTGCTAGC

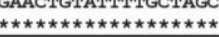

Figure 2 The alignment of the sequence P1-P2 with the sequence of the gene At2g21490. Alignment was generated using the CLUSTAL OMEGA program Nucleotides which are conserved in the sequences aligned are marked by asterisks. Dashes show sequence that is important for polyadenylation of mRNA The arrows outline the position of primers P1 and P2. The sequence of the primers $\mathrm{P} 1$ and $\mathrm{P} 2$ are in the boxes.

a)

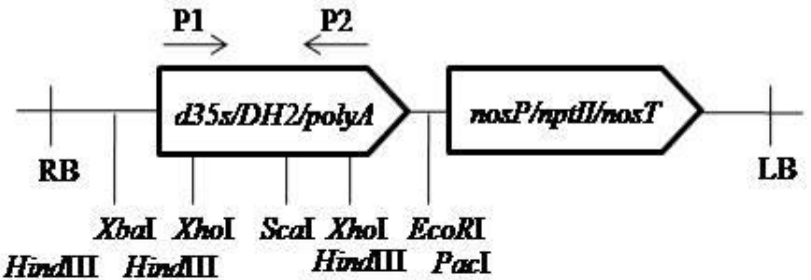

b)

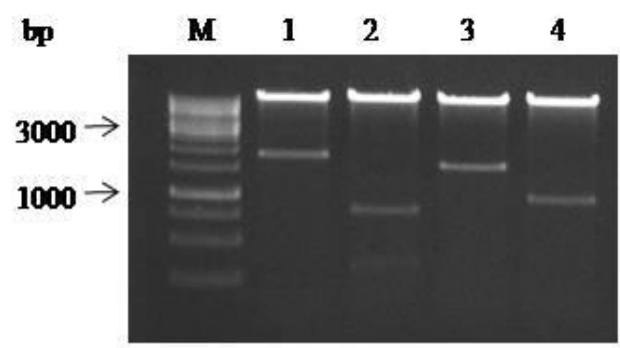

Figure 3 Restriction map and restriction analyses of the T-DNA-pDH2. a) TDNA structure of the $\mathrm{pDH} 2$. The primers used for PCR analyses are indicated as $\mathrm{P} 1, \mathrm{P} 2$. The position of restriction enzymes used in restriction analyses is indicated b) Photograph of the ethidium bromide-stained $1 \%$ agarose gel carrying in lane $\mathrm{M}-1 \mathrm{~kb}$ DNA marker (Fermentas), lane $1-\mathrm{pDH} 2 /$ EcoRI+XbaI, lane 2 - pDH2/ XhoI, lane 3 - pDH2 / HindIII, lane 4 - pDH2/ Asc I+ScaI. 
a)

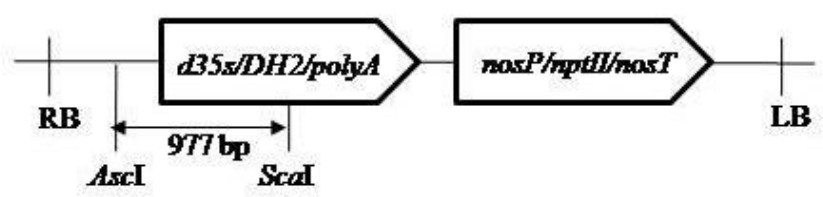

b)

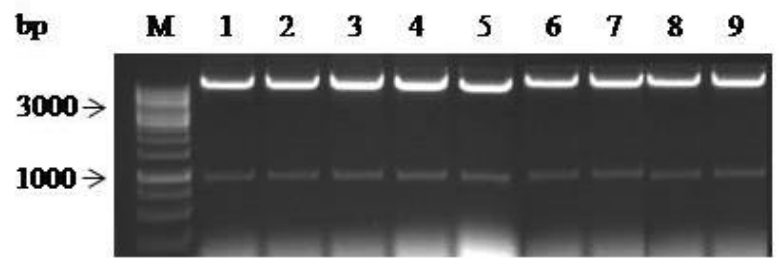

Figure 4 Restriction analyses of the T-DNA-pDH2 after re-transformation of plasmid into E. coli. a) The plasmid $\mathrm{pDH} 2$ with the position of restriction enzymes used in analyses. b) Photograph of the ethidium bromide-stained $1 \%$ agarose gel carrying in lane M - $1 \mathrm{~Kb}$ DNA marker (Fermentas); lanes 1-9 $\mathrm{pDH} 2 / A s c \mathrm{I}+$ ScaI .

\section{CONCLUSION}

Using the techniques of recombinant DNA a plant transformation vector $\mathrm{pDH} 2$ was prepared. The T-DNA region of the $\mathrm{pDH} 2$ contained Arabidopsis gene At2g21490 under control of the constitutive $d \mathrm{CaMV} 35 \mathrm{~S}$ promoter and selectable marker $n p t I I$ gene providing resistance to the antibiotic kanamycin. The binary vector $\mathrm{pDH} 2$ has been shown to be stable in A. tumefaciens LBA 4404. In future, A. tumefaciens LBA 4404 carrying the plant transformation vector $\mathrm{pDH} 2$ will be used for transformation of tobacco leaf explants.

Acknowledgments: This work was funded by the Slovak Grant Agency VEGA project 2/0035/17, by the institutional resources within the University Grant Agency UKF UGA VIII/32/2017 and by the project APVV-15-0051.

\section{REFERENCES}

Allagulova, C. R., Gimalov, F. R., Shakirova, F. M., Vakhitov, V. A. (2003). The plant dehydrins: Structure and putative functions. Biochemistry-Moscow, 68 (9), 945-951. http://dx.doi.org/10.1023/a:1026077825584

Amara, I., Zaidi, I., Masmoudi, K., Ludevid, M. D., Pages, M., Goday, A., Brini, F. 2014. Insights into Late Embryogenesis Abundant (LEA) proteins in plants: from structure to the function. In American Journal of Plant Sciences. č. 5, s. 3440-3455. http://dx.doi.org/10.4236/aips. 2014.522360

Candat, A., Paszkiewicz, G., Neveu, M., Gautier, R., Logan, D.C., AvelangeMacherel, M.E., Macherela, D. (2014). The Ubiquitous Distribution of Late Embryogenesis Abundant Proteins across Cell Compartments in Arabidopsis Offers Tailored Protection against Abiotic Stress. The Plant Cell, 26, 3148-3166. http://dx.doi.org/10.1105/tpc.114.127316

Close, T.J. (1997). Dehydrins: A commonalty in the response of plants to dehydration and low temperature. Physiologia Plantarum, 100, 291-296.

Hara, M., Fujinaga, M., Kuboi, T. 2005. Metal binding by citrus dehydrin with histidine-rich domains. Journal of Experimental Botany, 56 (420), 2695-2703. http://dx.doi.org/10.1093/jxb/eri262

Hara, M. (2010). The multifunctionality of dehydrins: an overview. Plant signaling behavior, 5 (5), 503-508. http://dx.doi.org/ 10.4161/psb.11085

Hara, M., Kondo, M., Kato, T. (2013). A KS-type dehydrin and its related domains reduce $\mathrm{Cu}$-promoted radical generation and the histidine residues contribute to the radical-reducing activities. Journal of Experimental Botany, 64 (6), 1615-1624. https://doi.org/10.1093/jxb/ert016

Hundertmark, M., Hincha, D. K. (2008). LEA (Late Embryogenesis Abundant) proteins and their encoding genes in Arabidopsis thaliana. Bmc Genomics, 9 (119). http://dx.doi.org/118 10.1186/1471-2164-9-118

Chen, Z., Greenblatt, I. M., Dellaporta, S. L. 1992. Molecular analysis of Ac transposition and DNA replication. Genetics, 130 (3), 665-676. ISSN 1943-2631. Matzke, M. A., Matzke, A. J. M. (1986). A set novel Ti plasmid-derived vectors for the production of transgenic plants. Plant Molecular Biology, 7 (5), 357-365. Rorat, T., Grygorowicz, W. J., Irzykowski, W., Rey, P. (2004). Expression of KS-type dehydrins is primarily regulated by factors related to organ type and leaf developmental stage during vegetative growth. Planta, 218 (5), 878-885. http://dx.doi.org/10.1007/s00425-003-1171-8
Vaculková, E., Moravčíková, J., Matušíková, I., Bauer, M., Libantová, J. (2007). A modified low copy number binary vector pUN for Agrobacterium-mediated transformation. Biologia Plantarum, 51 (3), 538-540. ISSN 0006-3134.

Van Engelen, F. A., Molthof, J. W., Conner, A. J., Nap, J. P., Pereira, A., Stiekema, W. J. (1995). pBINplus: an improved plant transformation vector based on pBin19. Transgenic Research, 4, 288-290. 